\title{
ESTUDO DAS ALTERNATIVAS PARA A MELHORIA DO EMPREENDIMENTO FEMININO: DOCES E CONSERVAS FRUTOS DO VALE
}

\author{
A STUDY ON ALTERNATIVES \\ FOR IMPROVEMENT OF THE \\ FEMALE ENTERPRISE "CANDIES \\ AND CANNED VALLEY FRUITS"
}

\author{
Pércia Graczyk de Souza* \\ Amanda Loiola de Carvalho ** \\ Cristina Sanini ${ }^{* * *}$ \\ Santino Seabra Júnior ${ }^{* * * *}$ \\ Aparecida de Fátima Alves de Lima ${ }^{* * * * *}$ \\ Alessandra Regina Butnariu ${ }^{* * * * * *}$ \\ Tadeu Miranda de Queiroz \\ Raimundo Nonato Cunha de Franca
}

\section{RESUMO}

O estudo buscou identificar as dificuldades enfrentadas nas etapas do agro-processamento e comercialização dos produtos do empreendimento feminino Doces e Conservas Frutos do Vale, da Comunidade Vale do Sol II, em Tangará da Serra-MT, e desta forma, propor alternativas passíveis de aplicação à realidade local. $O$ papel da mulher na agricultura familiar vem ganhando destaque, devido à criação de grupos femininos que desempenham atividades alternativas, com o intuito de aumentar a renda familiar. Mas, observa-se ainda inúmeras dificuldades que envolvem o preconceito de gênero, acesso à infraestrutura adequada e inserção dos produtos ao mercado. Diante desse contexto, foi possível sugerir alternativas aplicáveis em curto prazo para auxiliar as integrantes do empreendimento, como a criação de um cardápio sazonal, inserção de novas linhas produtivas, reaproveitamento de resíduos das matérias-primas, acondicionamento dos produtos, ferramentas de comercialização e controle financeiro.

Palavras-chave: Agricultura familiar. Fruticultura. Horticultura. Agro-processamento.

\footnotetext{
* Aluna de Mestrado da Universidade do Estado de Mato Grosso (UNEMAT), MT - Brasil. E-mail: graczykpercia@gmail.com

** Aluna de Mestrado da Universidade do Estado de Mato Grosso (UNEMAT), MT - Brasil. E-mail: amandinha_v@hotmail.com

*** Aluna de Mestrado da Universidade do Estado de Mato Grosso (UNEMAT), MT - Brasil. E-mail: cris.sanini@hotmail.com

**** Professor da Universidade do Estado de Mato Grosso (UNEMAT), MT - Brasil. E-mail: santinoseabra@hotmail.com

***** Professora da Universidade do Estado de Mato Grosso (UNEMAT), MT - Brasil. E-mail: afal.lima@gmail.com

****** Professora da Universidade do Estado de Mato Grosso (UNEMAT), MT - Brasil. E-mail: alebut@unemat.br

******* Professor da Universidade do Estado de Mato Grosso (UNEMAT), MT - Brasil. E-mail: tdmqueiroz@yahoo.com.br

******** Professor da Universidade do Estado de Mato Grosso (UNEMAT), MT - Brasil. E-mail: raimundofranca@unemat.br
} 


\section{ABSTRACT}

This study aimed at identifying the difficulties faced by the female enterprise "Candies and Canned Valley Fruits" from the Community Sun Valley II of Tangará da Serra-MT, during the phase of agro-processing and marketing, and at offering them possible alternatives. The women's contribution to family farming has been gaining momentum due to the formation of female groups that are involved in alternative activities to increase the family income. However, there are still many difficulties regarding gender bias, access to adequate infrastructure and the product launch in the market. Nonetheless, it was possible to offer alternatives to be applied in short term which provide assistance for the members of the enterprise about planning seasonal menus, launching new product lines, recycling raw material waste, product packaging, marketing strategies and financial control.

Keywords: Family agriculture. Orcharding. Horticulture. Agro-processing.

\section{Introduçáo}

A agricultura familiar no Brasil exerce grande importância para a economia interna e abastecimento de alimentos no país. De acordo com o Ministério do Desenvolvimento Agrário (2015), grande parte do território brasileiro é composto pelo meio rural, onde 5,2 milhōes representam estabelecimentos de produtores de alimentos, e $84 \%$ dos mesmos são responsáveis por grande parte da cesta básica dos brasileiros, tais como: mandioca, feijão, milho, carne suína, leite, carne de aves, entre outros.

Dentro dessa produção, cabe destacar o papel da mulher nas atividades agrícolas. A mulher trabalha há muito tempo no desempenho da agricultura, porém sua identidade é ocultada pelo trabalho desenvolvido pela família (homens, mulheres, filhos, idosos), e definido apenas como atividades domésticas, resultando na invisibilidade da mulher no meio rural (HEREDIA, 1979; GARCIA JR., 1993). Embora existam discursos que priorizam o domínio masculino no campo, esse contexto vem apresentando alteraçóes e a mulher vem ganhando seu devido protagonismo.

Estudos desenvolvidos por Galizoni e Ribeiro (2004), em Minas Gerais, apontam que as mulheres agricultoras da região desempenham atividades na lavoura, além de atividades domésticas, e dessa maneira ajudam suas famílias na produção. De acordo com Siliprandi (2007), por serem reconhecidas pelo trabalho na terra, muitas estão conseguindo conquistar alguns direitos, como tal, o acesso à terra. Cabe ressaltar que o papel da mulher não se limita somente no trato com a roça, ela é responsável pela introdução de novas linhas de produção, cultivo e empreendimentos rurais, desenvolvendo alternativas culinárias, artesanais, entre outras. Muitas dessas alternativas são conquistadas com muito esforço, vencendo não só o preconceito de gênero, mas também as dificuldades de inserção no mercado e exigências legais e sanitárias.

Diante desse contexto, este estudo descritivo teve como objetivo identificar as dificuldades enfrentadas pelo empreendimento feminino da Comunidade Vale do Sol II, em Tangará da Serra-MT, durante as etapas do agro-processamento da matéria-prima e comercialização dos produtos, e propor alternativas possíveis de serem aplicadas à realidade local.

\section{Surgimento e contextualizaçáo do empreendimento Frutos do Vale}

O município de Tangará da Serra está localizado na regiáo Sudeste do estado de Mato Grosso (Latitude 14,61 $\mathrm{O}$ S Longitude 57,48 $\mathrm{W}$ ), e conta atualmente com 94.289 habitantes, que predominantemente desempenham atividades econômicas baseadas na prestação de serviços, na agroindústria e agricultura (IBGE, 2015). 
É na zona rural, a $19 \mathrm{~km}$ do perímetro urbano, que se localiza a comunidade Vale do Sol II, ou também conhecida como Bezerro Vermelho. Seus moradores praticam a agricultura familiar, e se destacam por suas unidades produtivas em açóes que visam desenvolver habilidades gerenciais e organizacionais, melhorando, assim, a qualidade de vida dos pequenos agricultores do local (LIMA; COSTA, 2012). Além da importância para a produção agropecuária, a agricultura familiar apresenta capacidade de geraçáo de renda e emprego através de outras iniciativas, como a comercialização de produtos elaborados a partir das matérias-primas disponíveis no meio rural (JUNQUEIRA; LIMA, 2008), contribuindo para a fixação do homem no campo.

Em meio às inúmeras dificuldades referentes à organização da produção e infraestrutura insuficiente da Comunidade Vale do Sol II, foi criado, em 2010, um grupo composto por mulheres com o intuito de produzir doces e conservas, na sede social da Associação de Mulheres Rurais (AMFRUVALE), para aumentar a renda familiar. Nomeado "Frutos do Vale", surgiu num cenário de condiçôes precárias para a produção, no entanto, com várias motivaçóes para a construção do empreendimento (LIMA; COSTA, 2012).

No princípio, o grupo "Doces e Conservas Frutos do Vale" era composto por dez mulheres que elaboravam os doces com doaçōes de frutas e de açúcar, feitas pelas próprias integrantes. Foi a partir de um curso do SENAR (Serviço Nacional de Aprendizagem Rural) que o grupo estabeleceu contatos entre o NUPES (Núcleo de Políticas de Economia Solidária do Município de Tangará da Serra), Sindicato dos Trabalhadores Rurais juntamente com o SENAR, Prefeitura municipal e UNEMAT (Universidade do Estado de Mato Grosso), tornando possível a realização de outros cursos de capacitação, que proporcionou a participaçáo destas mulheres em eventos artísticos, culturais e comemorativos do município de Tangará da Serra-MT.

Além disso, a participaçáo em treinamentos, como: Boas Práticas de Manipulação de Alimentos, realizado com o apoio da UNEMAT; e Boas Práticas de Higienizaçáo, realizado com o apoio da Vigilância Sanitária, permitiram a aprovaçáo do empreendimento e a obtenção do Selo Municipal de Inspeção (SIM), o tornando legal frente às regulamentaçóes exigidas.

A comercialização dos produtos ocorria inicialmente entre amigos, familiares e clientes da feira livre municipal, fato que permitiu ao grupo de mulheres adquirirem novos utensílios e adaptar a cozinha da sede social da Associação, dentro das exigências mínimas de boas práticas de manipulação dos alimentos, favorecendo a ampliação da produçáo.

\section{O agro-processamento da matéria-prima local}

As mulheres do empreendimento Frutos do Vale adquirem a matéria-prima de agricultores da própria comunidade rural, seja cedia ou vendida por seus moradores. Foram realizados acompanhamentos através de visitas técnicas, em que se observou, sistematicamente, os principais produtos da horticultura e fruticultura da comunidade utilizados pelas mulheres para a produção dos doces e das conservas.

No entanto, constatou-se que o grupo encontra dificuldades para a aquisiçáo da matéria-prima, como no caso do leite, encontrado em quantidade insuficiente em 
determinados períodos do ano para atender a demanda dos consumidores; e também, como os produtos da horticultura e fruticultura, pois estes possuem sazonalidade. Além disso, carecem de eletrodomésticos (freezers) para seu devido armazenamento, entre outros utensílios e equipamentos necessários para produção agroindustrial. Por esta razáo, sugeriu-se a elaboração de um cardápio contendo os doces e as conservas que poderiam ser produzidos de acordo com a sazonalidade das matérias-primas, a fim de um melhor ordenamento de produção (Quadro 1).

\section{Quadro 1 - Disponibilidade da matéria-prima conforme sazonalidade}

\begin{tabular}{|c|c|c|c|c|c|c|c|c|c|c|c|c|}
\hline \multirow{2}{*}{ Produtos } & \multicolumn{12}{|c|}{ Meses de produção da matéria-prima } \\
\hline & Jan. & Fev. & Mar. & Abr. & Mai. & Jun. & Jul. & Ago. & Set. & Out. & Nov. & Dez. \\
\hline Abacaxi & & & & $x$ & $x$ & $x$ & $\mathrm{x}$ & & & & & \\
\hline Abóbora & $x$ & $x$ & $x$ & & & & & & $x$ & $x$ & $x$ & $x$ \\
\hline Amendoim & & & & & & $x$ & $x$ & $x$ & $\mathrm{x}$ & $x$ & & \\
\hline Banana* & $x$ & $x$ & $x$ & $x$ & $x$ & $x$ & $x$ & $x$ & $x$ & $x$ & $x$ & $x$ \\
\hline Caju & & & & & & & & & $x$ & $\mathrm{x}$ & $x$ & $\mathrm{x}$ \\
\hline Côco & $x$ & $x$ & $x$ & & & & & $x$ & $x$ & $x$ & $x$ & $x$ \\
\hline Figo & $x$ & $x$ & $x$ & $x$ & & & & & & & & $x$ \\
\hline Goiaba & $x$ & $x$ & $x$ & $x$ & & & & & & & & \\
\hline Laranja & & & $x$ & $x$ & $x$ & $x$ & $x$ & & & & & \\
\hline Mamão & $x$ & $x$ & $x$ & $x$ & $x$ & $x$ & $x$ & $x$ & $x$ & $x$ & $x$ & $x$ \\
\hline Maracujá & $x$ & $x$ & $x$ & $x$ & $x$ & $x$ & & & & & & \\
\hline Jabuticaba & & & & & & & & & $x$ & $x$ & $x$ & $\mathrm{x}$ \\
\hline Pitanga & & & & & $x$ & $x$ & & & & & & \\
\hline Milho & & & $x$ & $x$ & & & & & & $x$ & $x$ & $x$ \\
\hline Pepino* & $x$ & $x$ & $x$ & $x$ & $x$ & $x$ & $x$ & $x$ & $x$ & $x$ & $x$ & $x$ \\
\hline Quiabo* & $x$ & $x$ & $x$ & $x$ & $x$ & $x$ & $x$ & $x$ & $x$ & $x$ & $x$ & $x$ \\
\hline Maxixe* & $x$ & $x$ & $x$ & $x$ & $x$ & $x$ & $x$ & $x$ & $x$ & $x$ & $x$ & $x$ \\
\hline Cenoura/repolho* & $x$ & $x$ & $x$ & $x$ & $x$ & $x$ & $x$ & $x$ & $x$ & $x$ & $x$ & $\mathrm{x}$ \\
\hline Couve-flor ${ }^{*}$ & $x$ & $x$ & $x$ & $x$ & $x$ & $x$ & $x$ & $x$ & $\mathrm{x}$ & $\mathrm{x}$ & $x$ & $x$ \\
\hline Abobrinha* & $x$ & $x$ & $x$ & $x$ & $x$ & $x$ & $x$ & $x$ & $x$ & $x$ & $x$ & $x$ \\
\hline
\end{tabular}

*Se houver irrigação o ano todo.

As frutas e hortaliças exercem a cada dia uma maior participação na agricultura familiar, devido ao menor grau de processamento até o produto final (GUILHOTO et al., 2007).

De acordo com Simão (1998), o valor econômico da fruticultura não se situa somente na produção de frutas in natura para o mercado consumidor, e sim no aproveitamento de frutos para a industrialização, gerando um bem-estar social, alimentar e econômico. Igualmente, Faulin e Azevedo (2003) afirmam que as hortaliças apresentam um grande valor comercial e de subsistência, pois na agricultura familiar tornam-se importantes por se tratar de uma cultura que necessita de uma pequena extensão de terra.

A comunidade Vale do Sol possui outros produtos ainda não explorados pelo empreendimento feminino (Quadro 2). 
Quadro 2 - Produtos ainda náo explorados e sugestáo para o agro-processamento

\begin{tabular}{|l|l|}
\hline Frutas e fruto & Forma de beneficiamento \\
\hline Araçá-boi & $\cdot$ Geleias (GOMES et al., 2010) \\
\hline Cajá Manga & $\cdot$ Geleias (SILVA et al., 2013) \\
\hline Tomate & - Tomate seco (NOGUEIRA et al., 2003) \\
\hline Mangaba & $\cdot$ Geleias (OLIVEIRA et al., 2012) \\
\hline Cagaita & $\cdot$ Geleias (SANTOS et al., 2012) \\
\hline Pequi & • Pectina (SIQUEIRA et al., 2012) \\
& $\cdot$ Doces (SILVA et al., 2014) \\
\hline
\end{tabular}

Visando proposiçóes que possam favorecer o aumento da diversidade de produção e, consequentemente, a renda do grupo Doces e Conservas Frutos do Vale, explorou-se a ação das participantes, que além da intenção de inserir novas linhas produtivas, têm interesse em reaproveitar resíduos e subprodutos gerados nos beneficiamentos já existentes (Tabela 3).

\section{Quadro 3 - Resíduos e subprodutos dos beneficiamentos} já existentes e as formas de reaproveitamento

\begin{tabular}{|l|l|}
\hline Resíduos e subprodutos & Formas reaproveitamento \\
\hline Casca de abacaxi & $\begin{array}{l}\text { - Farinhas (MARTIN et al., 2012) } \\
\text { - Geleias (FERNANDES, 2012) }\end{array}$ \\
\hline Casca de maracujá & $\begin{array}{l}\text { - Farinhas (CAZARIN et al., 2014) } \\
\text { - Pectina (ARRIGONI et al., 2013) } \\
\text { - Doces (FERNANDES, 2012) } \\
\text { • Geleias (DIAS et al., 2011) }\end{array}$ \\
\hline Casca de manga & $\begin{array}{l}\text { - Pectina (RODRIGUES, 2009) } \\
\text { • Farinhas (MENDES, 2013) }\end{array}$ \\
\hline Casca de banana & $\begin{array}{l}\text { - Farinhas (NETO et al., 1998) } \\
\text { - Doces em pastas (VIZU et al., 2012) }\end{array}$ \\
\hline Casca de abóbora & - Farinhas (SANTOS, 2013) \\
\hline Semente de abóbora & - Aperitivos salgados e farinhas (VERONEZI; JORGE, 2012) \\
\hline
\end{tabular}

No processamento da cocada, são descartadas cascas de côco, que podem servir como matéria-prima na confecção de artesanatos para decoraçáo das embalagens, atribuindo-lhes características próprias. Além disso, a prática incentivaria a criação de novos grupos na Comunidade Vale do Sol II, o que originaria renda, e, ao mesmo tempo, reduziria os impactos ambientais causados pelos descartes em demasia de subprodutos agroindustriais.

De acordo com Santana (2005), a reduçáo do acúmulo de resíduos e subprodutos obtidos durante o processamento de alimentos alia-se ao interesse econômico, quando são criadas alternativas para o aproveitamento dos mesmos.

\section{As embalagens utilizadas pelo empreendimento}

A etapa final do processamento dos doces e conservas envolve a utilização das embalagens que acondicionam os produtos e propiciam a sua comercializaçáo. Com isso, foi possível observar uma adequação de embalagens de vidro para os doces e as conservas 
dos tipos geleia, doce em pedaços com calda, doce em pasta e conservas da horticultura (Figura 1).

Figura 1 - Embalagem final dos doces e conservas

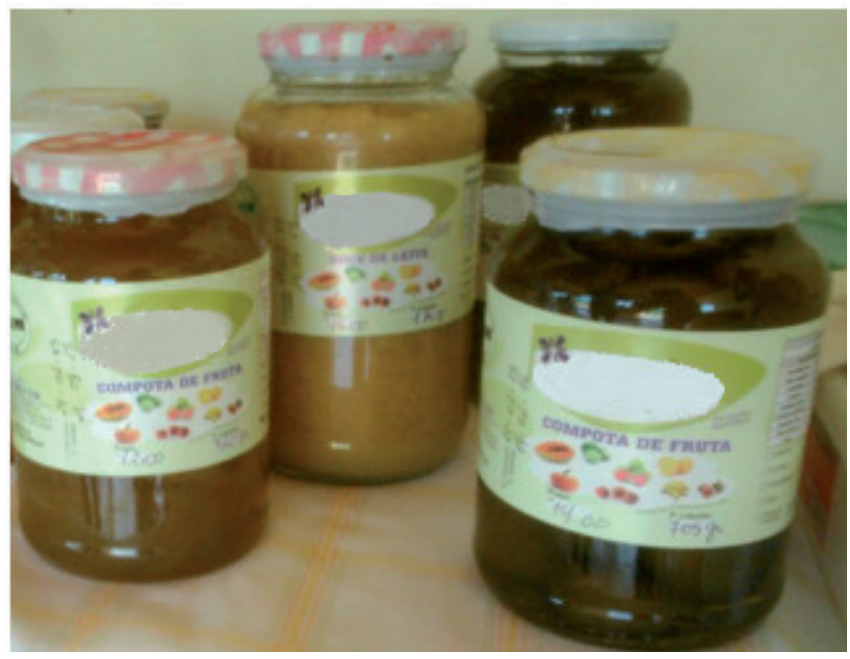

Já para os doces em pedaços produzidos no empreendimento Frutos do Vale, foram sugeridas embalagens individuais de plástico, juntamente com a rotulagem contendo especificaçóes do produto, ou até mesmo, unidades de doces em bandeja de isopor, envolvidas por plástico do tipo filme de policloreto de polivinila $(P V C)$, pois estes ainda sáo comercializados sem embalagens apropriadas para o tipo de produto. A sugestáo pode viabilizar a comercialização dos doces em pedaços, pois embalagens do tipo individual, utilizando plástico filme de $P V C$, teria um custo aproximado de $\mathrm{R} \$ 0,025$ por unidade, ao passo que a opção pelas bandejas, $R \$ 0,173$.

Sabe-se que a maioria das técnicas utilizadas em processamentos de alimentos necessita de embalagens adequadas para cada tipo de produto (SANTOS; OLIVEIRA, 2012). As embalagens têm como principal finalidade proteger os alimentos contra quaisquer açōes de deterioração ou contaminação após o processamento, assegurando a qualidade do produto ao consumidor final (SOUSA et al., 2012).

Além disso, Faria e Sousa (2008) retratam que posteriormente à ocorrência de mudanças no cenário econômico e sociocultural no país e às novas exigências dos consumidores, surgiram preocupaçóes com aspectos estéticos dos produtos, a fim de atrair a intenção de compra, através da embalagem. Soma-se a isso a proposição do incentivo à devoluçáo dos vidros pelos próprios consumidores. Esta alternativa pode se apresentar viável na minimização dos custos do empreendimento, como também de possíveis danos causados à natureza.

De acordo com Motta (2011), a importância da reutilização de embalagens se baseia na ideia de um planejamento reverso de pós-consumo, com o intuito de reduzir descartes inadequados, que geram impactos ao meio ambiente. 


\section{A comercializaçáo dos produtos}

O grupo Frutos do Vale faz parte de uma realidade da agricultura familiar em âmbito nacional, que encontra em atividades secundárias novas maneiras para complementar a renda. A atividade desenvolvida enfrenta muitos desafios também na fase de comercializaçáo dos produtos. Uma das dificuldades observadas no acompanhamento feito através das visitas técnicas é com relação à divulgação dos produtos, pois as mulheres não possuem condições financeiras para investir em meios de comunicação, tornando-a limitada a clientes que já realizam compras, sem possibilidade, portanto, de atingir novos públicos. Dessa forma, torna-se necessário desenvolver alternativas para auxiliar a divulgação dos produtos e alcançar novos clientes.

Sabe-se que a associação das mulheres possui uma fan page, ação oportunizada por uma rede social para auxiliá-las na divulgaçáo dos produtos, contudo, as integrantes náo utilizam e também não acompanham a página, alegando dificuldades quanto ao manuseio da ferramenta. Cabe, então, salientar sobre a importância da inclusão digital nessa associação. Levando-se em conta essa necessidade, sugere-se, a princípio, que as associadas realizem cursos introdutórios de informática, que podem ser ofertados e acompanhados por projetos de extensão e parcerias com a UNEMAT, e a partir da integração dessa iniciativa, a inclusão digital pode beneficiar a associação através de canais de divulgaçáo gratuitos.

Segundo Silva et. al. (2005), a inclusão digital é o ponto inicial ao acesso à informação, assimilação e reelaboração de um novo conhecimento, almejando como resultado a melhoria na qualidade de vida das pessoas. Os autores ressaltam a importância da inclusão digital na forma de educação através da informação, que necessita de políticas públicas mais engajadas para proporcionar às pessoas e organizaçóes o acesso informacional.

A partir da inclusão digital, é possível criar estratégicas para viabilizar a comunicação do empreendimento, visto que a comunicação é um ponto que deve ser considerado de grande importância para se ter excelência na comercialização dos produtos. Através de um estudo aprofundado nessa temática, é possível melhorar os canais de distribuição e criar oportunidades para difundir a marca de determinado produto, e até mesmo se tornar referência no segmento esperado.

Dentro dessa perspectiva, propóe-se desenvolver uma página em uma rede social para fazer divulgação dos produtos, tal como apresentar fotos dos doces e as conservas disponíveis para venda, disponibilizar o contato para futuras encomendas, e, também, um cardápio virtual contendo as variedades de produtos que são feitos na comunidade. Fotos de participação em eventos ou cursos realizados pelas integrantes são interessantes, além de outras possibilidades existentes na rede.

A distribuição de folders é também uma alternativa que pode auxiliar na efetividade de indicaçóes para esse tipo de negócio e atingir o público que não utiliza as redes sociais. A associação poderá contratar a impressão de folders para serem distribuídos em pontos-chaves da cidade, onde haja grande circulaçáo de pessoas, como faculdades, creches particulares, lojas de roupas, eventos em geral, entre outros. O mesmo pode conter informaçóes dos produtos, imagens e o telefone de contato para compras e encomendas. Nesse tipo de divulgação, é aconselhável que a associação realize orçamentos 
com as empresas que disponibilizam esse serviço, para analisar o preço e se pode ser economicamente rentável.

A divulgação pela internet é caracterizada por Souza (2013) como ações de marketing on line, que abrange as redes sociais para realizar a exposiçáo dos produtos, e a publicidade por folders envolve o canal off line, delineado como o marketing boca a boca. No primeiro canal, existem variados tipos de redes sociais, com destaque para o Facebook, que além de ser um canal gratuito, é considerado pela autora a principal rede de comunicação para expandir uma marca.

Cobra (2009) reforça esse pensamento, quando aborda que a internet proporciona a oportunidade de atrair novos compradores, juntando os conceitos de anúncio e venda em uma única proposta. Las casas (2008) complementa que os consumidores podem se sentir impulsionados a comprar pela influência desses canais, seja pelo efeito da persuasáo produzido na comunicação ou pela informação que adquirem.

Além do exposto, devido à falta de fornecedor de embalagens na cidade, a cozinha de doces artesanais náo consegue comprá-las com custo reduzido. Apesar das barreiras existentes, é possível encontrar possibilidades para auxiliá-las a conseguir o retorno das embalagens através da logística reversa. Dessa maneira, a alternativa encontrada é a realizaçáo de campanhas com os clientes para conscientizá-los a devolver as embalagens dos doces e conservas, utilizando incentivos de descontos. Essa ação pode ser propagada através das divulgaçóes sugeridas anteriormente e pelas próprias integrantes no momento de vender os produtos.

De acordo com Brito (2012), as empresas necessitam buscar vantagens competitivas, isto é, uma capacidade de criaçáo de valor acima da média de seus concorrentes, que pode ser alcançada também pela adoção de práticas simples, mas que contribui com a sociedade.

\section{Controle financeiro das vendas}

No acompanhamento realizado junto à sede da Associaçáo da Comunidade Vale do Sol II, as integrantes afirmaram que possuem o caderno como uma ferramenta que as auxiliam a controlar os custos, onde são anotados quantos doces foram produzidos e quantos foram vendidos. Embora seja uma associação pequena, o controle da gestáo deve ser considerado e adaptado à realidade da cozinha de doces artesanais.

Sugeriu-se um acompanhamento mais preciso da produção e das vendas, através de instrumentos de coleta de dados que contenham as principais informaçóes da quantidade produzida, relaçáo dos produtos, valor dos mesmos e a quantidade vendida. Dessa forma, é possível adequar a gestáo de controle à realidade da cozinha de doces e conservas, e, mesmo sendo uma pequena mudança, pode auxiliá-las de maneira eficiente na questão financeira. Nesse aspecto, torna-se interessante o uso de uma planilha, que pode ser inserida primeiramente de forma manual e, após o conhecimento básico de informática, ser adaptada ao controle, através da ferramenta Excel, por exemplo. Esta teria a função de controlar a produção e venda dos Doces e Conservas Frutos do Vale, contendo os principais tópicos para suprir as necessidades primárias de gestão de vendas da cozinha de doces e conservas. 
Gazzoni (2003) relata que o controle da gestão é uma ferramenta essencial para o desenvolvimento de qualquer organização, pois ela proporciona análise contínua dos resultados esperados e contribui para tomada de decisão. Muitos estudos evidenciam a importância do conjunto de ferramentas de controle aplicadas à gestão de um negócio. $\mathrm{Na}$ visão de Silveira (2002), a empresa precisa gerenciar o número de vendas e o comportamento que faz esse número acontecer, pois a empresa deve analisar o total de faturamento diário, a venda por produto durante a semana e quanto cada um vendeu. Isso só pode ser avaliado através de uma boa ferramenta de controle.

\section{Uma análise Swot para o empreendimento feminino}

Segundo Daychouw (2007), a matriz Swot consiste em uma ferramenta utilizada para desenvolver análises de cenários internos e externos e, a partir das informaçóes produzidas, se tornar uma base para o planejamento estratégico e para a tomada de decisão.

A partir do contexto, foi possível desenvolver uma análise Swot contendo uma síntese dos resultados obtidos no acompanhamento feito à associação das mulheres (Quadro 4), com o intuito de auxiliá-las na elaboração de futuras estratégias de melhoria do empreendimento, posterior ao repasse dos resultados desse estudo através de visita técnica, e com auxílio de folhetos informativos.

\section{Quadro 4 - Matriz Swot desenvolvida para o grupo Frutos do Vale}

\begin{tabular}{|c|c|}
\hline Pontos Fortes & Pontos Fracos \\
\hline $\begin{array}{l}\text { - Variedade de produtos; } \\
\text { - Cursos ofertados por parceiros (Prefeitura, Universidade, Nupes); } \\
\text { - Engajamento entre as integrantes; } \\
\text { - Qualidade dos produtos; } \\
\text { - Aceitação dos consumidores; } \\
\text { - Sval da Vigilância Sanitária; } \\
\text { - pelo para os produtos. }\end{array}$ & $\begin{array}{l}\text { - Não possuem a cozinha adequada; } \\
\text { - Falta de utensílios adequados; } \\
\text { - Falta de eletrodomésticos e } \\
\text { equipamentos essenciais; } \\
\text { - Falta de automóvel próprio } \\
\text { do empreendimento para } \\
\text { aquisição de matéria-prima e } \\
\text { distribuição do produto final. }\end{array}$ \\
\hline Oportunidades & Ameaças \\
\hline $\begin{array}{l}\text { - Busca por produtos artesanais; } \\
\text { - Apoio de Projetos de Extensão; } \\
\text { - Elaboração de cardápio; } \\
\text { - Aproveitamento das cascas de determinados frutos e legumes } \\
\text { para a formulação de novos doces e conservas; } \\
\text { - Novas alternativas de produtos com os frutos regionais ainda não utilizados; } \\
\text { - Alternativas de embalagens para os doces em pedaços, } \\
\text { proporcionando melhor condicionamento dos produtos; } \\
\text { - Desenvolvimento de alternativas para o aproveitamento das embalagens de } \\
\text { vidro através da logística reversa, gerando vantagens sustentáveis e econômicas; } \\
\text { - Possibilidade de inclusão digital na associação; } \\
\text { - Alternativas de divulgação atreladas aos benefícios da inclusão digital (fan } \\
\text { page no Facebook da associação dos doces e conservas, confecção de folders); } \\
\text { - Controle financeiro através de planilha manual } \\
\text { para auxílio da produção e venda diária. }\end{array}$ & $\begin{array}{l}\text { - Evasão de integrantes; } \\
\text { - Não utilizam propagandas ou } \\
\text { divulgação dos produtos; } \\
\text { - Entrada de concorrentes } \\
\text { advindos de outras comunidades, } \\
\text { voltadas para o mercado } \\
\text { de doces e conservas; } \\
\text { - Deficiência nas relações } \\
\text { interpessoais entre mulheres e } \\
\text { moradores da comunidade. }\end{array}$ \\
\hline
\end{tabular}

\section{Consideraçóes finais}

O acompanhamento realizado através de visitas técnicas à sede social da Associação de Mulheres Rurais permitiu identificar as dificuldades enfrentadas pelo grupo de mulheres, no que diz respeito às etapas produtivas e comercializaçáo dos produtos 
alimentícios do empreendimento Doces e Conservas Frutos do Vale. A partir disso, foi possível desenvolver opçóes que podem auxiliar as associadas a alavancar a venda dos produtos e atingir novos públicos, ao mesmo tempo em que geram a reduçáo dos custos e se tornam mais sustentáveis ao meio ambiente.

Cabe ressaltar que foram identificados, também, problemas relacionados à conflitos interpessoais e de estrutura organizacional decorrentes na Associaçáo. No entanto, o estudo em foco não visou abordá-los, e sim, propor alternativas passíveis de retorno em curto prazo quando aplicadas na realidade do local.

Assim, entende-se que este artigo possa vir a encorajar realizaçóes de outros estudos relacionados à proposiçáo de alternativas aplicáveis em curto prazo, para as cooperativas, associaçóes, comunidades, entre outras, uma vez que é reconhecida a carência de proposição de alternativas relativamente simples de serem aplicadas, além das diversas complexidades envolvendo o acesso a infraestrutura adequada e matériaprima suficiente.

Por isso, além das dificuldades citadas, sugere-se para futuras pesquisas ênfase nas vertentes relacionadas ao custo de produçáo e controle da gestấo, em treinamentos voltados ao manuseio de entradas e saídas, tal como a inserção de ferramentas de gerenciamento ideal para o ramo, como também o aprofundamento em pesquisas que visam desenvolver margens de produçáo através de análises referentes ao gerenciamento dos custos de produção e comercialização.

\section{Referências}

ARRIGONI, Bárbara Melotti et al. Reaproveitamento da casca do maracujá amarelo (Passiflora edulis flavicarpa) para a extração química de pectina com alto grau de esterificação. Enciclopédia Biosfera, Goiânia, v. 9, n. 16, p. 2942-2951, jun-jul. 2013.

BRASIL. Ministério do Desenvolvimento Agrário. Plano Estratégico 2015-2018. Brasília: MDA, Secretaria Executiva, 2015. 64p.

BRITO, Renata Pelegrino de; BRITO, Luiz Artur Ledur. Vantagem Competitiva, Criação de valor e seus efeitos sobre o Desempenho. RAE-Revista de Administração de Empresas, São Paulo, v. 52, n. 1, jan-fev. 2012.

CAZARIN, Cinthia B. B. et al. Capacidade antioxidante e composição química da casca de maracujá (Passiflora edulis). Ciência Rural, Santa Maria, v. 44, n. 9, p. 1699-1704, set. 2014.

COBRA, Marcos. Administração de marketing no Brasil. Rio de Janeiro: Elsevier, 2009.

DAYCHOUW, Merhi. 40 Ferramentas e Técnicas de Gerenciamento. Rio de Janeiro: Brasport, 2007.

DIAS, Marali V. et al. Estudo de variáveis de processamento para produção de doce em massa da casca do maracujá (Passiflora edulis f. flavicarpa). Ciência e Tecnologia de Alimentos, Campinas, v. 31, n. 1, p. 65-71, jan- mar. 2011. 
FARIA, Marcos Areas de; SOUSA, Caissa Veloso e. A influência da embalagem no composto de marketing. In: CONGRESSO NACIONAL DE EXCELENCIA EM GESTÃO, 4., Rio de Janeiro. Anais... Rio de Janeiro, 2008.

FAULIN, Evandro Jacóia; AZEVEDO, Paulo F. Distribuição de hortaliças na agricultura familiar: uma análise das transações. Informações Econômicas, São Paulo, v. 33, n. 11, p. 24-37. 2003.

FERNANDES, Alexandre. Cascas, Talos, Folhas e Outros Tesouros Nutricionais. Doces e sobremesas. Lisboa: Planeta Manuscrito, 2012. p. 233-272.

GALIZONI, Flávia Maria; RIBEIRO, Eduardo Magalhães. Trabalho feminino na agricultura familiar do Alto Jequitinhonha. In: CONGRESSO BRASILEIRO DE ECONOMIA E SOCIOLOGIA RURAL, 42., Cuiabá, 2004.

GARCIA JR., Afrânio Raul. O Sul: caminho do roçado. São Paulo: Marco Zero, 1989.

GAZZONI, Elizabeth Inez. Fluxo de caixa. Ferramenta de controle financeiro para a pequena empresa. 2003. Dissertação (Mestrado em Engenharia de Produção) Programa de Pós-Graduação em Engenharia de Produção, Universidade Federal de Santa Catarina, Florianópolis, 2003.

GOMES, Ronald B. et al. Avaliação físico-química de geleia de araçá-boi com banana. In: JORNADA CIENTÍFICA, Rio de Janeiro, 2010. Anais... Rio de Janeiro: Embrapa Mandioca e Fruticultura, 2010.

GUILHOTO, Joaquim J. M. et al. A importância da agricultura familiar no Brasil e em seus estados. Brasília: NEAD, 2007.

HEREDIA, Beatriz Maria Alásia de. A morada da vida: Trabalho familiar de pequenos produtores no Nordeste do Brasil. Rio de Janeiro: Paz e Terra, 1979.

IBGE. Instituto Brasileiro de Geografia e Estatística. Cidades: Tangará da Serra. Disponível em: <http://cidades.ibge.gov.br/xtras/perfil.php?codmun=510795|Public a\%C3\%A7\%C3\%A3o>. Acesso em: 05 jan. 2016.

JUNQUEIRA, Clarissa Pereira; LIMA, Jandir Ferrera de. Políticas públicas para a agricultura familiar no Brasil. Semina - Ciências Sociais e Humanas, Londrina, v.29, n. 2, p. 159-176, jul./dez. 2008.

LAS CASAS, Alexandre Luzzi. Administração de marketing: conceitos, planejamentos e aplicações à realidade brasileira. São Paulo: Atlas, 2008.

LIMA, Amadeu Nascimento. Um estudo sobre a importância do uso das ferramentas de controle gerencial nas micro, pequenas e médias empresas industriais no município de São Caetano do Sul. 2007. Dissertação (Mestrado 
em Administração) - Programa de Pós-Graduação em Administração, Universidade Metodista de São Paulo, 2007.

LIMA, Aparecida de Fátima A.; COSTA, Regina Maria. Apoio ao trabalho feminino na comunidade rural Vale do Sol II - Tangará da Serra MT. In: SEMINÁRIO DE EXTENSÃO UNIVERSITÁRIA DA REGIÃO CENTRO-OESTE, 5., Goiânia. Anais... Goiás: Universidade Federal de Goiás, 2012.

MARTIN, José Guilherme P. et al. Avaliação sensorial de bolo com resíduo de casca de abacaxi para suplementação do teor de fibras. Revista Brasileira de Produtos Agroindustriais, Campina Grande, v. 14, n. 3, p. 281-287, jul. 2012.

MENDES, Bruna de Andrade B. Obtenção, caracterização e aplicação de farinha das cascas de abacaxi e de manga. 2013. Dissertação (Mestrado em Engenharia de Alimentos) - Programa de Pós-Graduação em Engenharia de Alimentos, Universidade Estadual do Sudoeste da Bahia, Itapetinga, 2013.

MOTTA, Wladmir Henrique. Logística Reversa e a Reciclagem de Embalagens no Brasil. In: CONGRESSO NACIONAL DE EXCELENCIA EM GESTÃO, 7., Rio de Janeiro. Anais... Rio de Janeiro, 2011.

NETO, João Miguel de M. et al. Componentes químicos da farinha de banana (Musa sp.) obtida por meio de secagem natural. Revista Brasileira de Engenharia Agrícola e Ambiental, Campina Grande, v. 2, n. 3, p. 316-318. 1998.

NOGUEIRA, Regina Isabel et al. Manual para a Produção em Pequena Escala de Conserva de Tomate Desidratado. Rio de Janeiro: EMBRAPA, 2003. 19 p.

OLIVEIRA, Kênia B. et al. Elaboração e análise sensorial de geleia de mangaba com açúcar mascavo. In: CONGRESSO DE PESQUISA E PÓS-GRADUAÇÃO DO CAMPUS RIO VERDE DO IFGOIANO, I., Rio Verde. Anais... Goiás: IFGoiano, 2012.

RODRIGUES, Luciana A. Contribuição ao estudo bioquímico de frutas tropicais e exóticas produzidas no Brasil: pectina, açúcar e proteína. 2009. Dissertação (Mestrado em Biotecnologia) - Universidade Estadual Paulista, Instituto de Química, Araraquara, 2009.

SANTANA, M. F. S. Caracterização físico-química de fibra alimentar de laranja e maracujá. 2005. Tese (Doutorado em Engenharia de Alimentos) - Faculdade de Engenharia de Alimentos, Universidade Estadual de Campinas, Campinas, 2005.

SANTOS, Dayane Angélica M. dos. Formulação de biscoito tipo cookie a partir da substituição percentual de farinha de trigo por farinha de casca de abóbora (Curcubita máxima) e albedo de maracujá amarelo (Passiflora edulis flavicarpa). 2013. Dissertação (Mestrado em Alimentos e Nutrição) - Programa de Pós-Graduação em Alimentos e Nutrição, Universidade Federal do Estado do Rio de Janeiro, Rio de Janeiro, 2013. 
SANTOS, Joana S.; OLIVEIRA, Maria Beatriz P. P. Alimentos frescos minimamente processados embalados em atmosfera modificada. Brazilian Journal of Food Technology, Campinas, v. 15, n. 1, p. 1-14, jan-mar. 2012.

SANTOS, Priscila R. G. et al. Geleia de cagaita (Eugenia dysenterica DC.): desenvolvimento, caracterização microbiológica, sensorial, química e estudo da estabilidade. Revista Instituto Adolfo Lutz, São Paulo, v. 71, n. 2, p. 281-290, fev-jun. 2012.

SILIPRANDI, Emma. Agroecologia, Agricultura Familiar e Mulheres Rurais. Revista Brasileira de Agroecologia, Porto Alegre, v. 2, n. 1, p. 845-849, fev. 2007.

SILVA, Dalmo H. F. et al. Viabilidade econômica do pequi (Caryocar brasiliense Camb.) e subprodutos na formação da renda dos produtores do Cerrado Brasileiro. Comunicação \& Mercado, Dourados, v. 3, n. 7, p. 4-15, jan-jun. 2014.

SILVA, Helena et al. Inclusão digital e educação para a competência informacional: uma questão de ética e cidadania. Revista Ciência da Informação, Brasília, v.34, n. 1, p. 28-36, jan-abr. 2005.

SILVA, Maria José S. et al. Elaboração e avaliação da qualidade sensorial e físicoquímica de geleia de cajá. Revista Verde de Agroecologia e Desenvolvimento Sustentável, Pombal, v. 8, n. 3, p. 27-31, jul-set. 2013.

SILVEIRA, Paulo. A lógica da venda. São Paulo: Atlas, 2002.

SIMÃO, Salim. Tratado de fruticultura. Piracicaba: FEALQ, 1998.

SIQUEIRA, Beatriz dos S. et al. Pectina extraída de casca de pequi e aplicação em geleia light de manga. Revista Brasileira de Fruticultura, Jaboticabal, v. 34, n. 2, p. 560-567, jun. 2012.

SOUSA, Luci Cleide. F. S. et al. Tecnologia de embalagens e conservação de alimentos quanto aos aspectos físico, químico e microbiológico. Agropecuária Científica no Semiárido, Campina Grande, v. 8, n. 1, p. 19-27, jan-mar. 2012.

SOUZA, Paola G. Plano de comunicação: empresa de doces artesanais Doce Mannia. 2013. Trabalho de Conclusão de Curso (Bacharelado em Administração) Departamento de Ciências Administrativas, Universidade Federal do Rio Grande do Sul, Porto Alegre, 2013. 
VERONEZI, Carolina M.; JORGE, Neuza. Aproveitamento de sementes de abóbora (Cucurbita sp.) como fonte alimentar. Revista Brasileira de Produtos Agroindustriais, Campina Grande, v. 14, n. 1, p. 113124, out. 2010.

VIZU, Juliana de Fátima. et al. Aproveitamento do Resíduo Orgânico da Casca de Banana na elaboração de Doces em Pasta. In: CONGRESSO NORTE NORDESTE DE PESQUISA E INOVAÇÃO, 7., Palmas. Anais... Palmas: Ciência, tecnologia e inovação, 2012. 